\title{
Nurse-Doctor Relationship in Rwanda: A Questionnaire Survey
}

\author{
MukeshimanaM ${ }^{1^{*}}$ and Asingizwe $\mathrm{D}^{2}$ \\ ${ }_{1,2 *}$ Madeleine Mukeshimana, BNAP; MsN, PhD ๑ Lecturer at the University of Rwanda, College of Medicine \\ and Health Sciences, PhD $\odot$ at the University of KwaZulu Natal, South Africa \\ ${ }^{2}$ Domina Asingizwe, Maasters in Research, PhD student Assistant Reseracher at the University of Rwanda, \\ College of Medicine and Health Sciences
}

\begin{abstract}
Background: As it is evident in literature review, the working relationship between nurses and doctors was dominant- subservient relationship in the ancient days and the studies show that this working relationship is still influenced by this template. However, even if this patriarchal relationship still exists, many nurses in these days do not want to continue the same game, they want to be independent in their profession. This change is not accepted by doctors who want to continue their dominant role; they are complaining that nurses are no longer obedient. This becomes the origin of doctor-nurse disagreements in their interaction in many hospitals and this influence the health care of patients. The study had three objectives: to identify the factors that can affect the nurse-doctor working relationships in a selected Hospital in Rwanda, to determine the causes of disputes and to find out the power relations between nurses and doctors within the Hospital management structures.

Methods: A quantitative descriptive study was conducted. The target population comprised 80 people working at the selected hospital. The non-probability convenience sampling was used to choose the sample size of 60 participants. Aself-report questionnaire was used for data collection and data were analyzed using descriptive statistics and were presented in tables and graphs.

Results: The majority of respondents have agreed that there are a number of factors contributing to misunderstandings and conflicts between nurses and doctors at the area of study. The existence of disputes is mostly caused by the behaviour of doctors who consider themselves as superiors. The results have revealed also that the hospital management do not treat with the same respect the doctors and nurses.

Conclusion: The findings revealed that lack of respect and consideration to others bring the conflicts, disputes and misunderstandings between doctors and nurses. Nurses who participated in the study advised that doctors should recognize nurses and respect them as independent professionals.
\end{abstract}

Keywords: Nurse-doctor relationships

\section{Introduction And Background}

Since the ancient days, nurses and doctors worked together towards a common goal, of saving people's lives. However this relationship has acquired the status of a special relationship. Historically doctors were viewed as superiors and nurse as inferiors, and in order to maintain the harmony in that relationship, nurses had to obey blindly the doctors' orders. [1]In the past, nurses' subordination to doctors has gone unquestioned. [2]Traditionally, doctors have been seen as the repositories of clinical knowledge and have been charged with keeping abreast of recent advances and imparting this knowledge not only to their own apprentices, but also to nurses within the team, doctors were educated whilst nurses were trained. [3]This inequality is generated in medical-nursing training as it is this apparent subservience to the doctors is inculcated early on in medical and nursing training. Doctors were taught to decide, and nurses were taught to obey the doctor's orders before they graduate. [3]

Even if this working relationship between nurses and doctors was dominant- subservient relationship in the ancient days, the studies show that the working relationship between nurses and doctors is still influenced by this template. Doctors still hold essential powers and responsibilities that have an impact on the nurse-doctor interdependence relationship. [3] Other author agreed also in the same way that relationship between nurses and doctors are based on a division of knowledge, power and authority. [2]

However, even if this patriarchal relationship still exists, many nurses in these days do not want to continue the same game of dominant-subservient, they want to be independent in their profession, to be respected as many nurses are wishing to move from dependency to autonomy, and mutual interdependence, they want to stand on an equal footing with doctors, because more nurses have become specialized and confident in their knowledge. $[1,3]$ The same authors continue by saying that many nurses, silently express resentment and act out their feelings, some become "silent saboteurs ", undermining or sabotaging, in a passive-aggressive way the decisions made by doctors. 
This change is not accepted by doctors who want to continue their dominant role in the nurse-doctor working relationship, they are complaining that nurses are no longer obedient, that these one want to consider themselves as doctors, which is impossible [5]. This disharmony in working relationships between these two professionals does not only negatively affect them but also it affects the care given to patients. The relationship between nurses and doctors in Rwanda is not explored, thus the researcher's arousal to study this relationships. The aim of this study was to explore the working relationships among nurses and doctors in one selected hospital.

\section{Methods}

For this study, a non-experimental descriptive design has been adopted. The research approach was quantitative and this study was exploratory-descriptive in nature.

The area of the study was one selected district hospital situated in East of Rwanda. The population for this study comprised all nurses and doctors working at the hospital at the time of the study. The total target population was 80 people (70 nurses and 10 doctors). The sample size comprised 60 people (50 nurses and 10 doctors). The non-probability convenience sampling was used where all nurses and doctors meeting the inclusion criteria, available and ready to participate in the study had the equal chance to be part of the sample size. The inclusion criteria were 6 months of working at the hospital.

A questionnaire was designed by the researcher guided by the supervisor using the objectives and literature review as point of departure. It had four main sections, namely socio-demographic, factors affecting nurse-doctor relationship, causes of disputes between nurses and doctors and power relations between nurses and doctors within the hospital management. It consisted of structured, closed-ended questions: single or multiple responses. It had been translated into the local language (Kinyarwanda) in order to allow common understanding among respondents. To ensure the reliability, the questionnaire was pre-tested with ten people from the area of the study who did not participate in the main study; the test-retest coefficient was 0.84 . In general, the correlation coefficients are considered good if they are at least 0.70 [6]. And the content validity was used to unsure the validity of questionnaire.

The researcher distributed the questionnaires to the participants and gave them time to complete them and return them the same day.

The questionnaire has been numbered and coded to facilitate data capturing and auditing of captured data. All variables were analyzed using the SPSS version 16.0 program. A statistician assisted with statistical analysis. Descriptive statistics were used to describe and synthesize data. Frequencies and basic statistics have been calculated and presented in tables and graphs. Data was numeric.

The study was carried out ethically by considering self- determinationwhererespondents' right to selfdetermination was assured by explaining the purpose and significance of the study to them and obtaining their informed consent to ensure voluntarism. Privacy, confidentiality and anonymity also were assured by using codes instead of their names and storage of the completed data collection tools in a safe, locked place. They were also ensured that they can withdraw any time and no further consequences. The permission of data collection was obtained from the selected hospital administration.

\section{Socio-demographic characteristics}

\section{Results}

Most respondents 53.3\% $(n=32)$ were male and $46.7(n=28)$ were female. Of respondents $11.7 \%(n=7)$ were under 25 years old, 55\% $(n=33)$ were between 26-35 years old, 30\% $(n=18)$ were between $36-45$ years old and $1.7 \%(n=1)$ were 46 years old and more. Of the respondents $45 \%(n=27)$ were single, $46.7 \%(n=28)$ were married, while $1.7 \%(n=1)$ were divorced and $6.7 \%(n=4)$ were widow. Of the respondents, $83.3 \%(n=50)$ were nurses while $16.7 \%(n=10)$ were doctors, this lead to $100 \%$ of our target sample in this study.

\section{Insert Table 1}

The causes of misunderstanding between nurses and doctors working at selected hospital

A half of respondents $51.7 \%(n=31)$ did not answer the question aimed to explore the causes of misunderstandings between nurses and doctors. $13.3 \%(n=8)$ out of $48.3 \%(n=29)$ who responded to this question, regarded the superiority of Doctors as the cause of misunderstanding between nurses and doctors. The rest of respondents have reported different causes of misunderstandings as it is shown in the table 2.

\section{Insert table 2}

\section{Disputes between nurses and doctors}

The results have shown that $33 \%(n=20)$ of respondents agreed that they have been in disputes with a nurse or a doctor, $65 \%(n=39)$ disagreed and $2 \%(n=1)$ were unsure. When the respondents who have been in disputes were asked the causes of that disputes; different causes were reported such as Lack of respect by the 
doctor, Refusal of nurse to execute the doctor`s order, Being insulted by the doctor before patients, Order from a doctor which is out of my scope of practice, Delay of the doctor to answer my call in emergency case and Errors in drug's administration and lack of attention to patient by nurses.

\section{Insert Table 3}

Equality of both nurses and doctors in terms of Hospital management

The majority of respondents $86.7 \%(\mathrm{n}=50)$ confirmed that there is no equality of both nurses and doctors in terms of hospital management at the area of study. $11.7 \%(\mathrm{n}=7)$ confirmed that there is equality and $5 \%(n=3)$ were not sure if there is equality or not.

\section{Insert Figure 1}

\section{Discussion \\ Factors which affect nurse-doctors working relationship}

In this study, more than a half $(53 \%, \mathrm{n}=32)$ of respondents agreed that nurses and doctors have misunderstandings between them. Working relations between nurses and doctors, as any set of relations between two collectives in the workplace, are affected to some degree by interprofessional conflicts. [2]

The participants in our study identified a list of factors able to cause misunderstandings between nurses and doctors. The doctors who consider themselves as superior than nurses was a factor cited by a high number of respondents. Different professions, personal skills, errors in drug's administration, lack of attention to patients and lack of respect by doctors were also factors reported by respondents as factors able to generate misunderstandings between two professionals. These findings agreed with [4], who found that factors able to cause misunderstandings between Doctors and Nurses can be grouped them into two categories: Personal factors and work related factors. They also added that, Doctors $(66.7 \%)$ were more likely than nurses $(57.5 \%)$ to suggest that inadequate development of interpersonal skill play a role in their working relationship. [4]

The lack of respect by doctors was also a factor reported in this study. These findings goes in same line with [8]who states that some physicians rudely overrule nurse's clinical concerns and subject nurses to verbal abuse and humiliation. The same author in Canada, continues by saying that the results of her study reveal that nurses told of being humiliated, screamed at, and subjected to temper tantrums as well as physical abuse, $90 \%$ of unions' members said they have been victims of at least one act of assault, or aggression during the career. This abuse has historically been accepted as an exercise in stress release, something doctors are allowed to do given their superior intellectual position, nurses don't like the abuse but they expect it, are grateful when it doesn't happen, and are reluctant to complain about it.[8]

The superiority, power and authority of doctors over nurses in their working relationship have been reported as factors in this study. These findings agreed with [8-11] and they attribute the dominance of medicine over nursing as the cause of doctors' superiority over nurses and make the observation that medicine dominates at several levels that is economically, politically, socially and intellectually.

\section{Disputes between nurses and doctors}

In in thisstudy, $33.3 \%$ of respondents have been in dispute with a nurse/doctor and $32 \%$ have witnessed a dispute between a nurse and a doctor. A nurse being insulted by a doctor before patients, the lack of respect by doctors and the refusal of nurses to take orders from doctors were the main causes of disputes in this study. Some studies have found similar factors to be major causes of disputes between nurses and doctors. [4, 5 , 7] There is also refusal of nurses to follow the doctor's orders as the main cause of their disputes. [5] Other studies state that nurses do no longer want to follow blindly the doctor's orders. Nurses are fighting for freedom and are in the process of establishing nursing as an autonomous profession; they are being less dependent on doctors, more confident and not acting so much in subordinate roles. [11, 12]

However nurses have made much progress toward improving the situation, because they don't articulate what they expect from doctors or how they'd like things to change. [12] The same author added that although nurses are increasingly offended by the nurse/doctor game, they still play it. Furthermore nursesplay a largely subservient and supportive role in maintaining the relationship'sstatus quo.[9]

Nurses wear a particular costume to play a particular role in nurse/doctor relationship in order to avoid open conflicts. [8] The cross-cultural study done in Mexico found that in Mexico and Italy, where more prescribed professional roles are maintained ( nurses are subordinate to physicians), there was less conflicts than in the United States and Israel, where professional roles appeared more complementary (for example, greater shared autonomy and mutual authority).[13]

Delay of the doctor to respond the nurse's call was also reported as the cause of disputes in the current study. These findings goes in the same line with $[12,14]$ who found that in most cases doctors don't respond immediately to the nurses' call, which has a negative impact on patient life in many cases. This doctor's delay to 
respond the nurses' call is interpreted by doctors as saving their time; according to the same authors, doctors hate being contacted repeatedly for minor issues and expected nursesto deal with these.

The refusal of doctors to take advice from nurses regarding the patient care and lack of simplicity were cited as the causes of disputes between nurses and doctors in the current study. The results were also agreed by [15] who state that through Doctor's monopoly over diagnosis and prescription, doctors decide who should be a patient and what should be done to them, nurses are never consulted nor allowed to give their advice; they are limited to assisting their medical superiors, to administering drugs and to maintaining a hygienic and comfortable environment of patients. In some cases doctors consider nurses as less intelligent reason why they refuse to take advice from them. [8]However nurses use informal overt strategies to involve themselves in decision-making sequences. [15] While nurses were ostensibly deferent to doctors, their deference masked a considerable input into health care decision making. This author claims that doctor nurse- game involve nurses making implicit recommendations through the use of statements about the condition of a patient, this masquerade enable doctors to utilize nurses' knowledge while maintaining the pretence of their own omniscience.[12]

Errors in drug administration were one of causes of disputes between nurses and doctors in this study. This factor also was found to be the cause of conflicts between nurses and doctors in their research. [4] In most cases, errors in drug administration are caused by overwork and role confusion of nurses. [16]The same author added that nurses don't have time to think and to act calmly, they are always under pressure; hospital administrators want their time used more productively to take better care of more patients with less cost, Physicians want it available at the time they need it to do their jobs better, faster, more easily, patients want more of staff nurses' time to help them cope with a system that is confusing, frightening and sometimes harmful and Nurse managers want it to be spent when scheduled, to do the work assigned. This causes the role confusion and overwork for nurses. The absence of correct and complete information was found also as the cause of errors in drug administration. [17] Doctors dictate their orders and lack to give necessary information. [17]The doctorasks the nurse to do something and expects the results, there is no mention here of the nurse questioning a doctorunless it is done with tact. This may led to the errors in performing those tasks by nurses. [12]

The majority of respondents identified personal skills as the main factor which can cause disharmony between nurses and doctors in the present study. Other factors cited by more than a half of participants are uncooperative work attitudes, refusal of doctors to take advice from nurses and lack of attention to patient care.These results go in the same line with [4] where all these factors were found to be the causes of disharmony between nurses and doctors. Others significant causes of disputes between nurses and doctors identified by participants in the current study were cultural demands of respect,different levels of education and different professions.Different levels of education between nurses and doctors shape their relationships. Both medicine and nursing education have perpetuated the "doctor knows best" perspective. According to this author, nurses, regardless of their level of education, are addressed by their first name, while doctors are always addressed as Dr.[8, 18]. Gender issues have beingconsideredas importance in explaining the position of nurses in nurse/doctor working relationships. [18].

\section{The equality of both nurses and doctors in terms of Hospital management}

The majority of participants in the current study confirmed that there is no equality of both nurses and doctors in terms of hospital management. These findings agreed with $[4,8]$ who stated in their studies that majority of nurses $(86.1 \%)$ compared to doctors $(29.2 \%)$ confirmed inequality between nurses and doctors regarding the hospital management. Relationship between nursing and medicine is further complicated by ways in which the roles of physicians and nurses are portrayed and prescribed within health care organizations. The same authors added that the managers don't recognize the nurses' efforts; they always attribute all best to the doctors. This inequality of both nurses and doctors was also found by $[19,20]$ where in most health care institutions, the management is in the doctors' hands. About $67 \%$ of the managers were doctors, and $28 \%$ were nurses.Doctors almost exclusively led the clinical directorates as clinical directors thus they were controlling all employees even nurses. [24] This inequality in Hospital management is related to the social construction of nursing as a "female role" and medicine as a "male role" therefore doctors have to lead and manage hospitals, because socially, men are naturally more instrumental, rational, scientific and decisive; while women are considered by society as possessing expressive, emotional and caring qualities.[15] This also was agreed by [21] who found that $76 \%$ of doctors in his study were dissatisfied by hospital management and considered it as inadequate, $47 \%$ considered the manager as an outsider to the health sector. Hospital managers consider nurses less intelligent and doctors genius reason why nurses are less or never consulted by managers regarding the decisions making. They contribute to the problems by making arbitrary decisions without the input ofnurses; ever-increasing bureaucratic complexity is hurting patients and driving talented doctors and nursesout of the profession. [22, 23] 


\section{Limitations of the study}

The exploration of relationships is a sensitive issue and a different methodology may produce different results. Answers received may also be reconstructions of respondent's experiences. Furthermore, respondents often tend to answer questions in what they consider to be a socially desirable manner.

The environment where this research was conducted may differ from others, leading to discrepancies in findings.

For this study, the sample was selected on the basis of convenience and consisted of nurses and doctors working at one selected district Hospital who volunteered to participate in the study. In non-probability sampling the probability that any person from a specific population will be selected is not known, therefore generalizability may be reduced. A further limitation of the current study is its sample size with its population. Because of financial limits of the researcher, the study was conducted in one hospital only in Rwanda, thus the findings can not be generalized in all hospitals. In future, studies on a larger target population with a larger sample size would be more ideal.

Despite these limitations, validity and reliability of instrument in this study suggested that the respondents responded with some consistency and appeared to find the measures comprehensible. Furthermore these limitations did not overshadow the strengths of the study. The major strength of this study is that it provides research into area in which working relationship between nurses and doctors have never been explored, in Rwanda. Apart that these results may benefit the actual subjects, they also make a helpful contribution to the literature of doctor working relationship in Rwanda. In addition they help validate previous literature and studies in field done in other areas.

\section{Conclusion}

There is general recognition in the literature that smooth working relationships between nurses and doctors are necessary for efficient health care delivery. The good collaboration between nurses and doctors does not promote the quality care only but affect positively both nurses and doctors.However, previous studies have shown that this is often absent with negative impact on the quality of health care delivery. The findings from this study revealed that lack of respect of nurses by doctors, insulting nurses before patients, delay of doctors to respond nurses' call in emergence cases with errors in drug administration were main factors reported by respondents to be causes of their disputes. The inequality treatment of both nurses and doctors by hospital managers was disclosed in our findings. Although it is important to understand the historical factors that have determined each profession's roles and responsibilities, as well as areas of conflict and disagreement, it is the mutual interdependence of nurses and doctors thatwill lead the way to true collaborative clinical work in their daily interaction.

\section{Acknowledgements}

Our sincere gratitude to the Educational Board of Rwanda which supported the study. Our deep thanks goes to Jennifer Deebeer for her valuable support during the study.

\section{Conflict of interests}

All authors report no conflict of interest.

\section{Authors' contributions}

MM conceived the idea for the manuscript, DA reviewed and provided substantial edits. All authors approved the final version.

Table 1: Sociodemographic characteristics

\begin{tabular}{|l|l|l|l|}
\hline Demographic characteristics & Frequency & Percentage \\
\hline \multirow{5}{*}{ Age } & Male & 32 & $53.3 \%$ \\
\cline { 2 - 4 } & Female & 28 & $46.7 \%$ \\
\cline { 2 - 4 } & Total & 60 & $100 \%$ \\
\hline & $<25$ years & 7 & $11.7 \%$ \\
\cline { 2 - 4 } & $26-35$ years & 33 & $55.0 \%$ \\
\cline { 2 - 4 } & $36-45$ years & 18 & $30.0 \%$ \\
\cline { 2 - 4 } & 46 years and more & 1 & $1.7 \%$ \\
\cline { 2 - 4 } & No response & 1 & $1.7 \%$ \\
\cline { 2 - 4 } & Total & 60 & $100 \%$ \\
\hline \multirow{5}{*}{ Marital status } & Single & 27 & $45.0 \%$ \\
\cline { 2 - 4 } & Married & 28 & $46.7 \%$ \\
\cline { 2 - 4 } & Divorced & 1 & $1.7 \%$ \\
\cline { 2 - 4 } & Widow & 4 & $6.7 \%$ \\
\cline { 2 - 4 } & Total & 60 & $100 \%$ \\
\hline \multirow{5}{*}{ Profession } & Nurse & 50 & $10.3 \%$ \\
\cline { 2 - 4 } & Doctor & 10 & $100 \%$ \\
\cline { 2 - 4 } & Total & 60 & \\
\hline
\end{tabular}


Table 2: Factors able to contribute to misunderstands and conflicts between nurses and doctors at Rwamagana Hospital

\begin{tabular}{|l|l|l|}
\hline Causes & Frequency & Percentage \\
\hline Mefiance & 3 & $5.0 \%$ \\
\hline Refusal to take orders from the doctor & 4 & $6.7 \%$ \\
\hline Doctors consider themselves as superior & 8 & $13.3 \%$ \\
\hline Lack of respect & 4 & $6.7 \%$ \\
\hline Different level of education & 1 & $1.7 \%$ \\
\hline Conflicts of interests and absence of procedures and strategies & $1.7 \%$ \\
\hline Personal skills & 1 & $1.7 \%$ \\
\hline $\begin{array}{l}\text { Different professions, personal skills, Errors in drug's administration, lack } \\
\text { of attention to patients }\end{array}$ & 5 & $8.3 \%$ \\
\hline Lack of respect and lack of attention to patient & 2 & $3.3 \%$ \\
\hline No response & 31 & $51.7 \%$ \\
\hline Total & 60 & $100 \%$ \\
\hline
\end{tabular}

Table 3: Causes of disputes between nurses and doctors at Rwamagana hospital

\begin{tabular}{|l|l|l|}
\hline Causes of disputes & Frequency & Percentage \\
\hline Lack of respect by the doctor & 4 & 6.7 \\
\hline Refusal of nurse to execute my order & 1 & 1.7 \\
\hline Being insulted by the doctor before patients & 3 & 5.0 \\
\hline Order from a doctor which is out of my scope of practice & 5 & $8.3 \%$ \\
\hline Delay of the doctor to answer my call in emergency case & 2 & 3.3 \\
\hline Lack of attention to patient by a nurse & 1 & 1.7 \\
\hline Errors in drug's administration and lack of attention to patient & 1 & 1.7 \\
\hline No response & 43 & 71.7 \\
\hline Total & 60 & $100 \%$ \\
\hline
\end{tabular}

Figure1: Equality of both nurses and doctors in terms of Hospital management

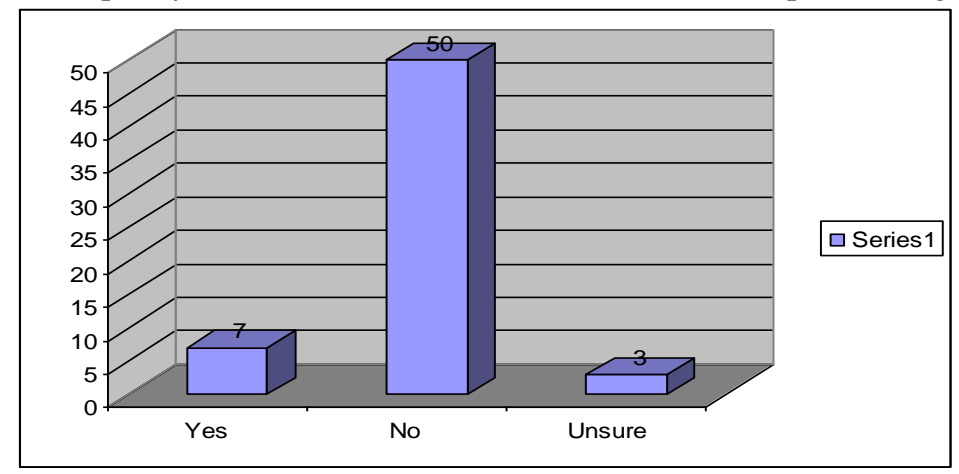

\section{References}

[1]. Radcliffe M. Personal views: Doctors and nurse: new game, same result. BMJ, 2000; 320(7241):1085-1095. Retrieved 15 September, 2008 from: http:// www.bmj.com/cgi/content/full/320/7241/1085

[2]. TabackN.and Koprak O. Relationship between how nurses resolve their conflicts with doctors, their stress and job satisfaction. Journal of Nursing management, 2007; 15(3): 321-331.

[3]. Fagin L, and Garelick A. The doctor-nurse relationship. Advances in Physiatrists treatment, 2004;(10) : 277-286. Retrieved 17 September, 2008 from: http: //apt.repsych.org/cgi/content/full/10/4/277.

[4]. Ogbimi I R, and Adebamowo A C. Questionnaire survey of working relationship between nurses and doctors in University Teaching Hospitals in Southern Nigerian. BMC Nursing, 2006; 5 (2) :1-5.

[5]. Demir B, and Kasapoglu A. Nurses physicians' relations: A qualitative case study in the Emergency Department of a hospital in Ankara, Turkey. EuropeanJournalofTurkishstudie, 2008. Retrieved August 30, 2008, from http://www.ejts.org/document1783.html, Retrieved 30 August, 2008

[6]. Litwin M S. How to assess and interpret survey psychometrics. The survey kit $-2^{\text {nd }}$ ed. London: Sage Publications.2003.

[7]. Qolohle MD, Conradie HA, Ogubanjo G A, and MaleteNH . A qualitative study on the relationship between doctors and nurses offering primary health at KwaNobuhle. South African Family Practice, 2006; 48 (1) :17a- 17e.

[8]. Gordon S. Nursing against the odds. How health care cost cutting, Media stereotypes, and Medical hubris undermine nurses and patients care. New York. Cornel: University press.2005.

[9]. Wicks D. Nurses and Doctors at Work: Rethinking Professional Boundaries. Allen \&Unwin, Sydney. 1999.

[10]. Jones R A. Conceptual development of nurse-physician collaboration. Holistic Nurse Practice, 1994; 8 (3):1-11.

[11]. SvenssonR.The interplay between doctors and nurses - a negotiated order perspective. Sociology of Health and Illness, 1996 ; 18 (3) : 379-398.

[12]. Stein L, Watts DT and Howell T."The Doctor-Nurse Game Revisited." The New' England Journal of Medicine, 1990;322(8): 546549.

[13]. Hojat M, Gonnella J, Nasca T, Fields S, Cicchetti A, Scalzo A, et al. Comparisons of American, Israeli, Italian and Mexican physicians and nurses on the total and factor scores of the Jefferson scale of attitudes toward physician-nurse collaborative relationships. International Journal of Nursing Studies, 2003; (40): 427-435. 
[14]. Patricia W I. Nursing malpractice. $2^{\text {nd }}$ ed. : Lawyers and judges Publishing Company. Inc.2001.

[15]. Porter S. Women in a women's job: the gendered experience of nurses. Sociology of Health \& Illness, 1992; 14(4).The Queen's University of Belfas.

[16]. Manthey F. The role confusion and overwork of nurses: Who Owns a Staff Nurse's Time? Creative Nursing ,1999; (2). Retrieved 22 September,2009 from http://web.ebscohost.com/ehost/pdf?vid=4\&hid=107\&sid=3b060485-84fb-4d33-ba8a00dfd29ef84e\%40sessionmgr10.

[17]. Rosenstein A. Nurse-physician relationships: Impact on nurse satisfaction and retention. American Journal of Nursing, 2002; 102(6): 26-34.

[18]. Mackay L. Physicians and Nurses: Working Together. Edinburgh Churchill Macmillan. 1993.

[19]. Degeling P, Zhang K, Coyle B, Meng O, Xu L, Jiangbin O and Hill M. Clinicians and the governance of hospitals: A cross-cultural perspective on relations between profession and management. Social Science \& Medicine, 2006;63(3): 757-775

[20]. Gjerberg E, Sørensen B A. Unified management in Norwegian hospitals--still controversial. Tidsskrift for Den Norske Laegeforening, 2006;126 (8) : 1063-1066

[21]. Thomas P. The interdisciplinary model ofhospital administration: do health professionals and managers look at it in the same way? European Journal of Public Health ,2008; 18 (1) : 71-76

[22]. Trenwith C. Wollongong Hospital discrimination case: 'Nurse hid from doctor'. 2009. Retrieved 25 September, 2009 from: http://www.illawarramercury.com.au/news/local/news/general/wollongong-hospital-discrimination-case-nurse-hid-fromdoctor/1579322.aspx

[23]. Lucy C. A doctor's scream.New Statesman, 2006; 135 (4822): 24-26

[24]. Coombs M, A. Power and conflicts between nurses and doctors. Breaking through the inner circle in clinical care. London: Routledge.2004. 